New hi gh- speed i nduct i on mot or dr i ven by a commer ci al source

\begin{tabular}{|l|l|}
\hline 著者 & Yamada Sot oshi, Takeuchi A. , Bessho Kazuo \\
\hline $\begin{array}{l}\text { j our nal or } \\
\text { publ i cat i on t i t l e }\end{array}$ & I EEE Tr ansact i ons on Magget i cs \\
\hline vol une & 23 \\
\hline number & 5 \\
\hline page r ange & $3020-3022$ \\
\hline year & 1987- 09-01 \\
\hline URL & ht t p: //hdl . handl e. net /2297/48314 \\
\hline
\end{tabular}




\title{
NEW HIGH-SPEED INDUCTION MOTOR DRIVEN BY A COMMERCIAL SOURCE
}

\author{
S.Yamada, A.Takeuchi*, K. Bes sho** \\ Dept. of Electrical and Computer Engineering, \\ Faculty of Technology, Kanazawa University \\ 2-40-20, Kodatsuno, Kanazawa 920, Japan \\ * Hokuriku Electric Power Company \\ 3-1. Sakurabashi Street, Toyama 930, Japan \\ * Electrical Energy Conversion Laboratory, \\ Faculty of Technology, Kanazawa University \\ $2-40-20$, Kodatsuno, Kanazawa 920, Japan
}

Abstract - This paper described the structure and characteristics of a new high-speed induction motor. The motor has the magnetic combination of an induction motor and a magnetic frequency tripler and is called a "hybrid motor". When the three-phase to twophase type tripler we proposed is adopted, this rotating-field type hybrid motor can be constructed. The motor has remarkable starting torque and operates near synchronous speed (10800 rpm) by only an application of a $60 \mathrm{~Hz}$ commercial source. It is noted that the motor has no semiconductor device and a brushless structure.

\section{INTRODUCTION}

The authors have developed the magnetic frequency multiplier (frequency tripler) for the application of high-speed motor operation. Since both the magnetic tripler and the motor have each magnetic circuit, the magnetic combination can simplify the structure. In the previous paper ${ }^{1}$, we reported the high-speed induction motor of a single phase and call it "hybrid motor". But the single-phase induction motor has one unavoidable defect, that is, starting torque. In order to remove it, we propose the rotating-field type hybrid induction motor and discuss the characteristics.

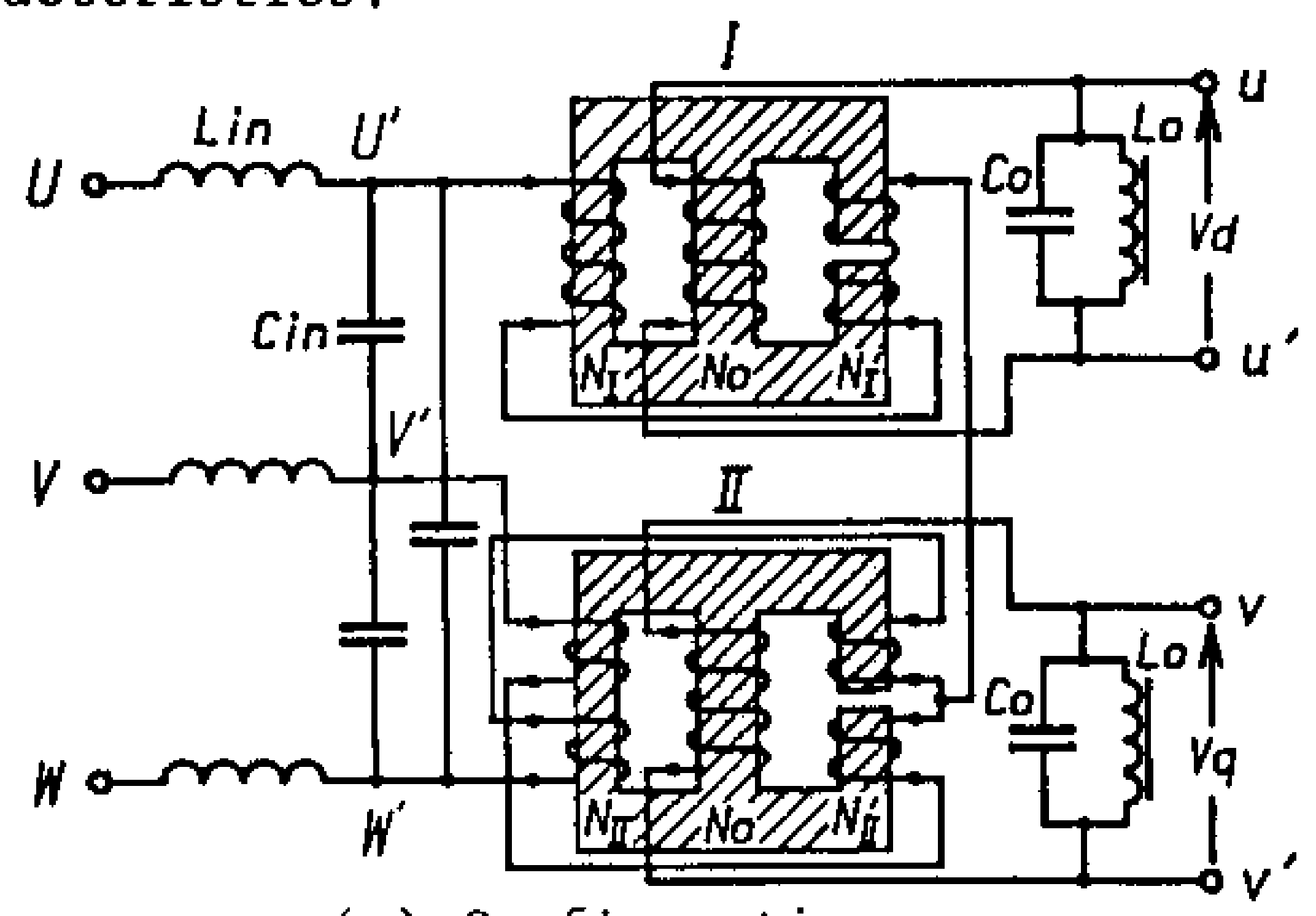

(a) Configuration

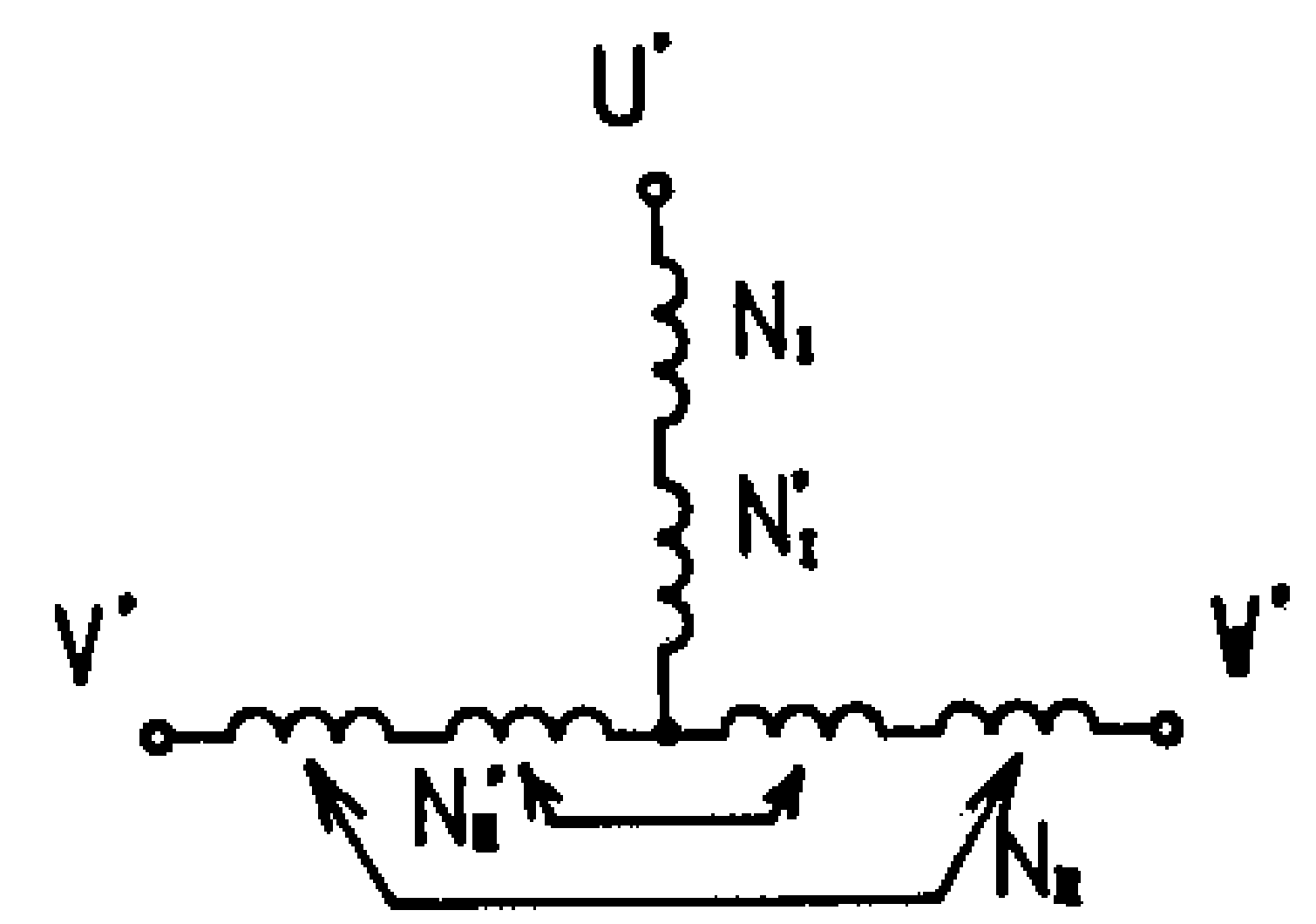

(b) Scott-connection in the primary windings Fig.l Three-phase to two-phase magnetic tripler

\section{STRUCTURE OF ROTATING-FIELD TYPE} HYBRID INDUCTION MOTOR

\section{(1) Three-phase to two-phase tripler}

Figure 1(b) shows the three-phase to twophase magnetic frequency tripler. In this configuration, two single-phase triplers(I, II) composed of 3-legged cores are connected in Scott-connection(Fig.1(b)). The circuit(LinCin) improves the power factor and expands the range of a operating input voltage. The parallel resonant circuit(Lo-Co) enhances the third harmonic voltage. The characteristics of the single-phase tripler are described in the literatures. ${ }^{2} 3$ The two-phase input voltages shifted at 90 degree are applied to two triplers. The output voltage of one tripler is given as,

$$
v_{d}(t)=\sum_{n=1}^{\infty} v_{2 n-1} \sin \left((2 n-1) \omega t+\theta_{2 n-1}\right)
$$

where $n, \theta_{2 n} 1$ and $v_{2}-1$ are integer, phase difference and peak ${ }^{1}$ alue of each harmonic respectively. As two triplers have the same structures, the output voltage of the other is expressed as,

$$
\begin{aligned}
V_{q} & (t+(\pi / 2 \omega)]= \\
\sum_{n=1}^{\infty} V_{2 n-1} & \sin \left((2 n-1) \omega t+(2 n-1) \pi / 2+\theta_{2 n-1}\right)
\end{aligned}
$$

Therefore, two third harmonic components of output voltages ( $V d, V q$ ) have the phase difference of 270 degree as a two-phase source. The phase sequence of a three-times frequency voltage rotates reversely against a fundamental frequency voltage.

(2) Structure of a new hybrid induction motor The structure and dimensions of the hybrid induction motor made are shown in Fig.2. The new induction motor has the magnetic combination of an induction motor and a magnetic frequency tripler in structure. The motor has two pairs of magnetic frequency multipliers (I, II) in four magnetic poles as shown in Fig.2(a). In each pole, the middle leg has a air-gap and the legs at both sides operate in magnetic saturation. The symmetrical configuration offers the stout structure. In operation, the magnetic poles(I, II) correspond to the triplers ( $I$, II) in Fig.l. But comparing the flux paths, the third harmonic flux generated at the poles flows through the rotor and the yoke in the motor.

Figure 2(b) shows the connection diagram between two poles. The coils at two poles are connected in the scott-connection and the relations between numbers of turns at each coil are expressed as,

$$
\mathrm{N}_{\mathrm{I}}=\sqrt{3} / 2 \mathrm{~N}_{\mathrm{I}}, \quad \mathrm{N}_{\mathrm{I}}^{\prime}=\sqrt{3} / 2 \mathrm{~N}_{\mathrm{I}}
$$

The capacitor Co is connected to the coil Nc. The reactor Lo in Fig.l corresponds with that 


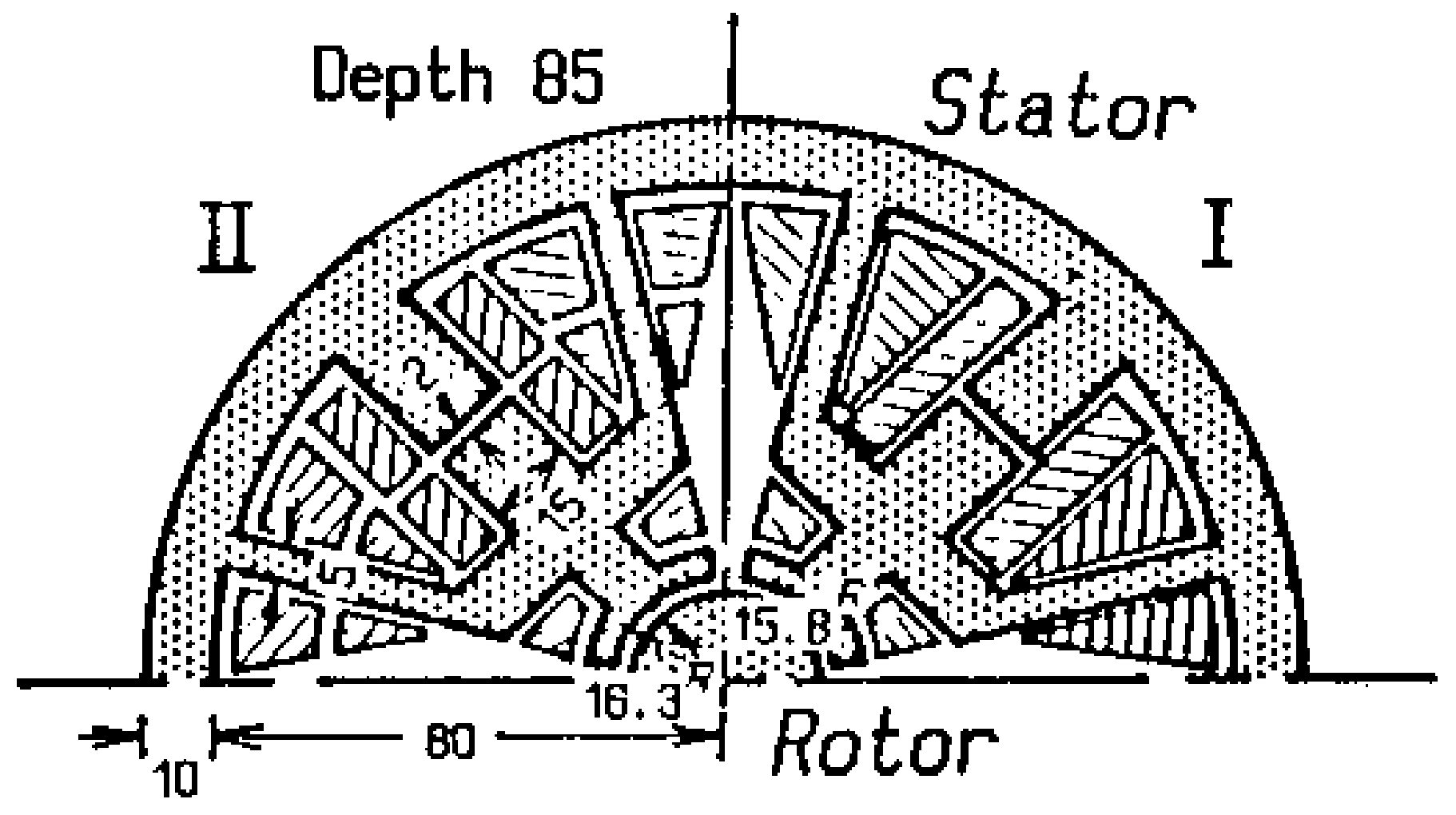

(a) Structure (1/2)

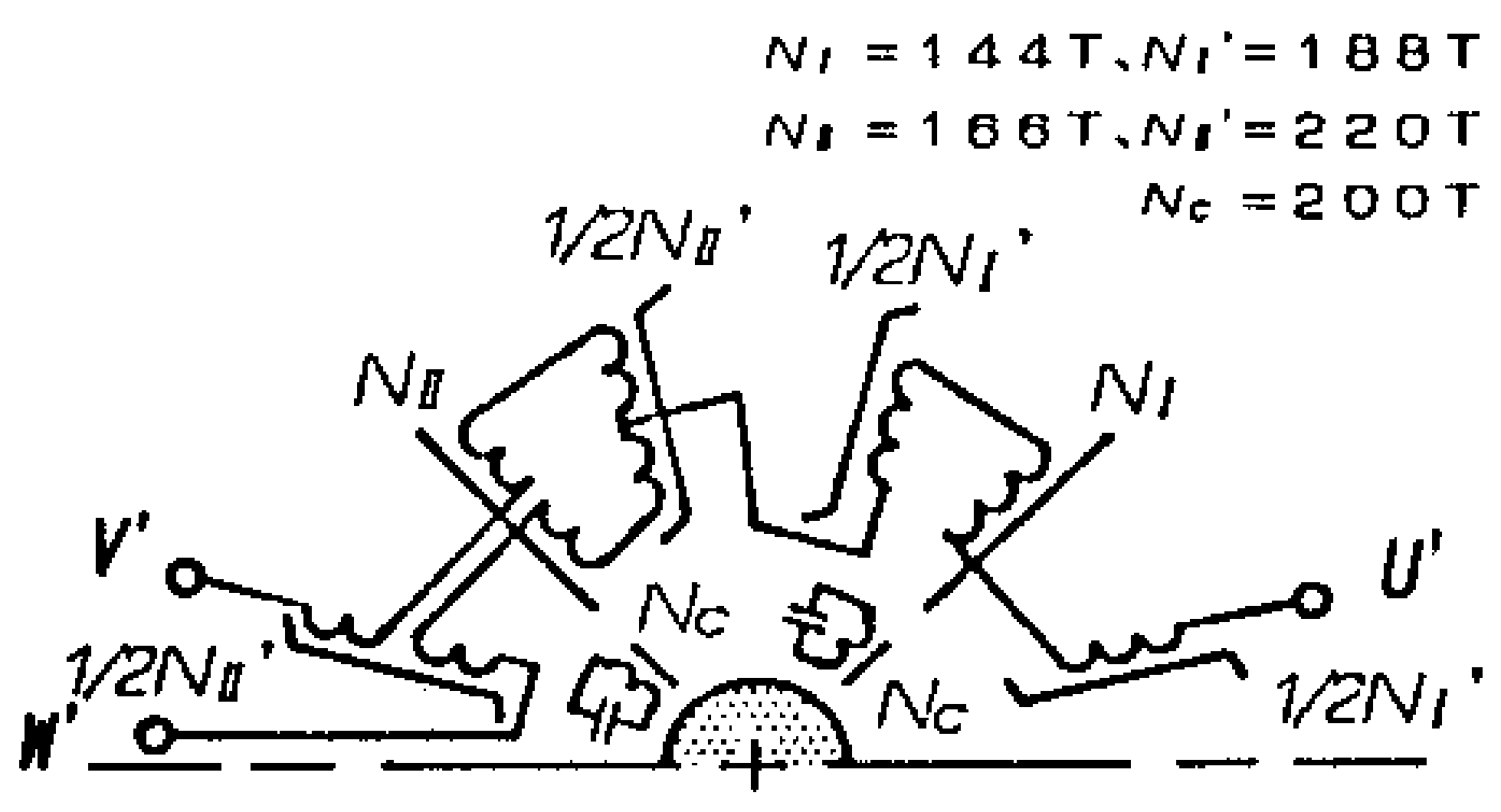

(b) Connection

Fig. 2 High-speed hybrid two-phase induction motor

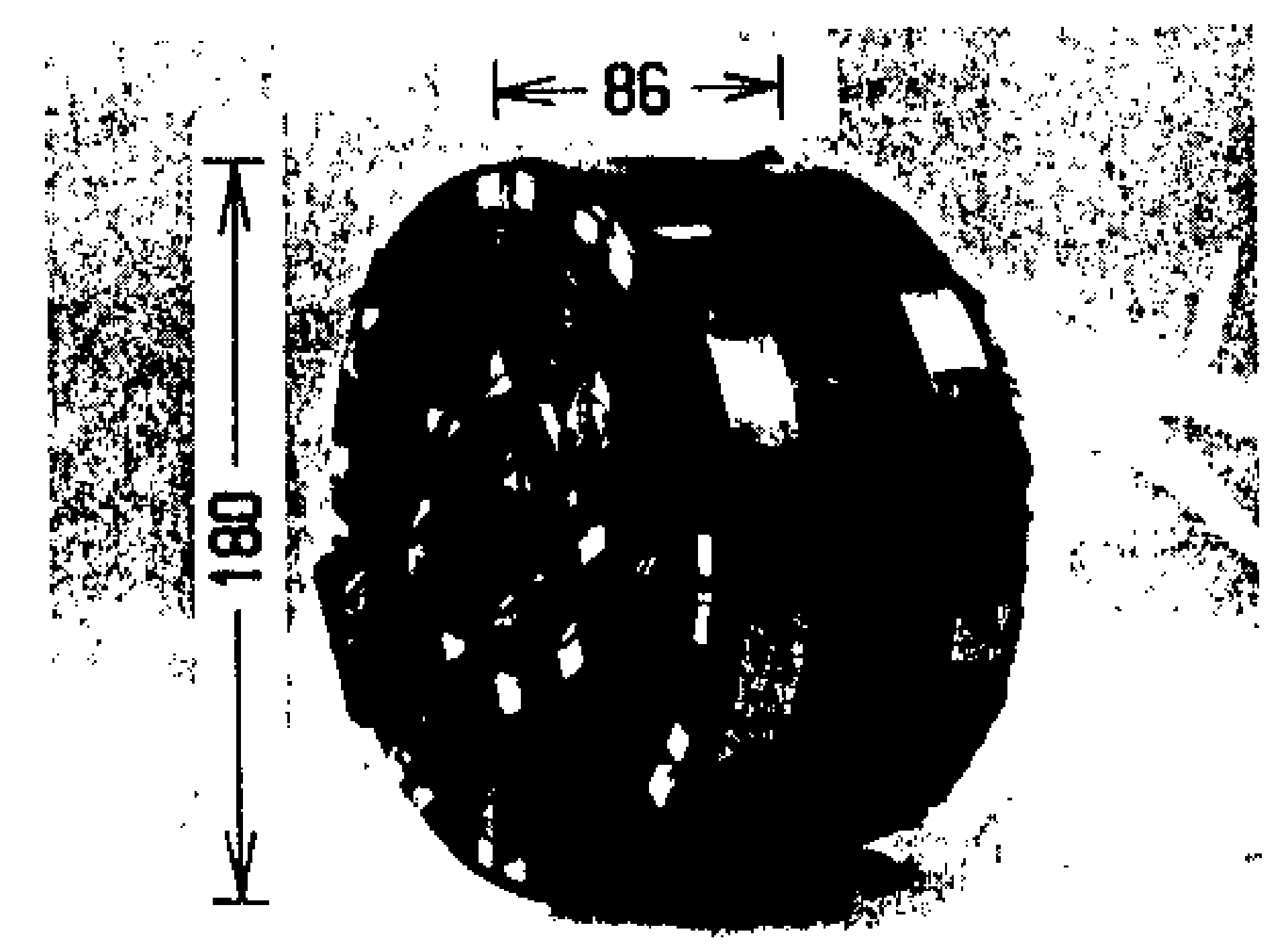

Fig. 3 Photograph of a new motor

based upon the gap between a stator and a rotor. The resonance(Co-Lo) enhances the threetimes frequency flux through the rotor and the pole. The circuit(Lin-Cin) is separately connected to terminals $\left(U^{\prime}, V^{\prime}, W^{\prime}\right)$.

- The photograph of the tested motor is shown in Fig.3. The stator is made of $0.35 \mathrm{~mm}$ silicon steel. The rotor is the conventional squirrel-cage type for commercial frequency.

\section{CHARACTERISTICS OF A HYBRID INDUCTION MOTOR}

\section{(1) Characteristics}

When a $60 \mathrm{~Hz}$ commercial source is applied to the hybrid motor and the rotor is locked. the characteristics as triplers are measured at the coil Nc. Figure 4 shows the frequency components of voltages as a function of an input voltage. For simplicity, the circuit (Lin-Cin) is removed. As the legs in the pole are saturated with increasing input voltage, the harmonics are generated and the Lo-Co resonant circuit enhances the third harmonic component. However, a fundamental and other harmonic voltages can not be suppressed. Figure 5 shows the Lissajous'figure of voltages

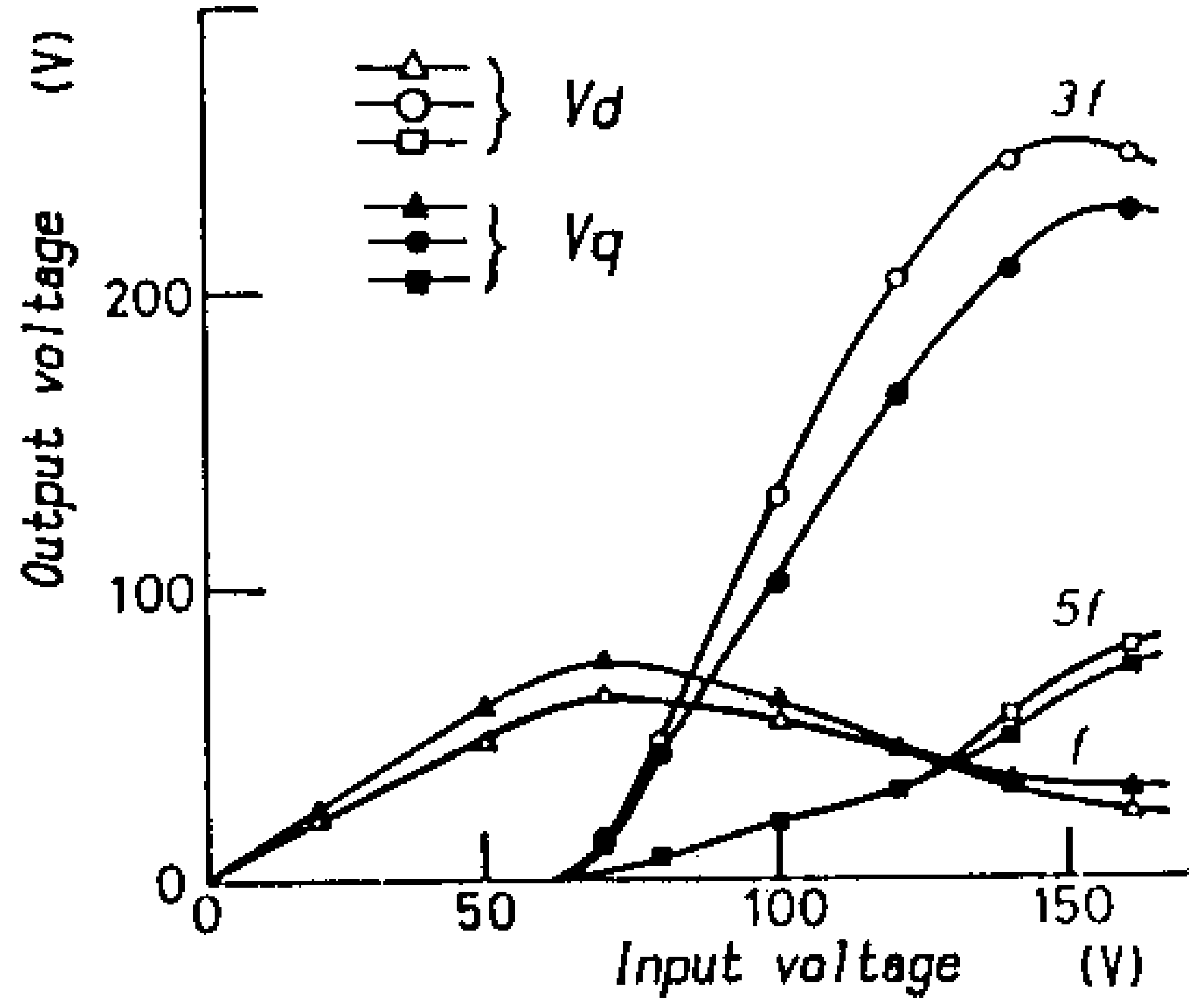

Fig. 4 Frequency components of the output voltages at the windings $\mathrm{NC}$ as a function of an input voltage

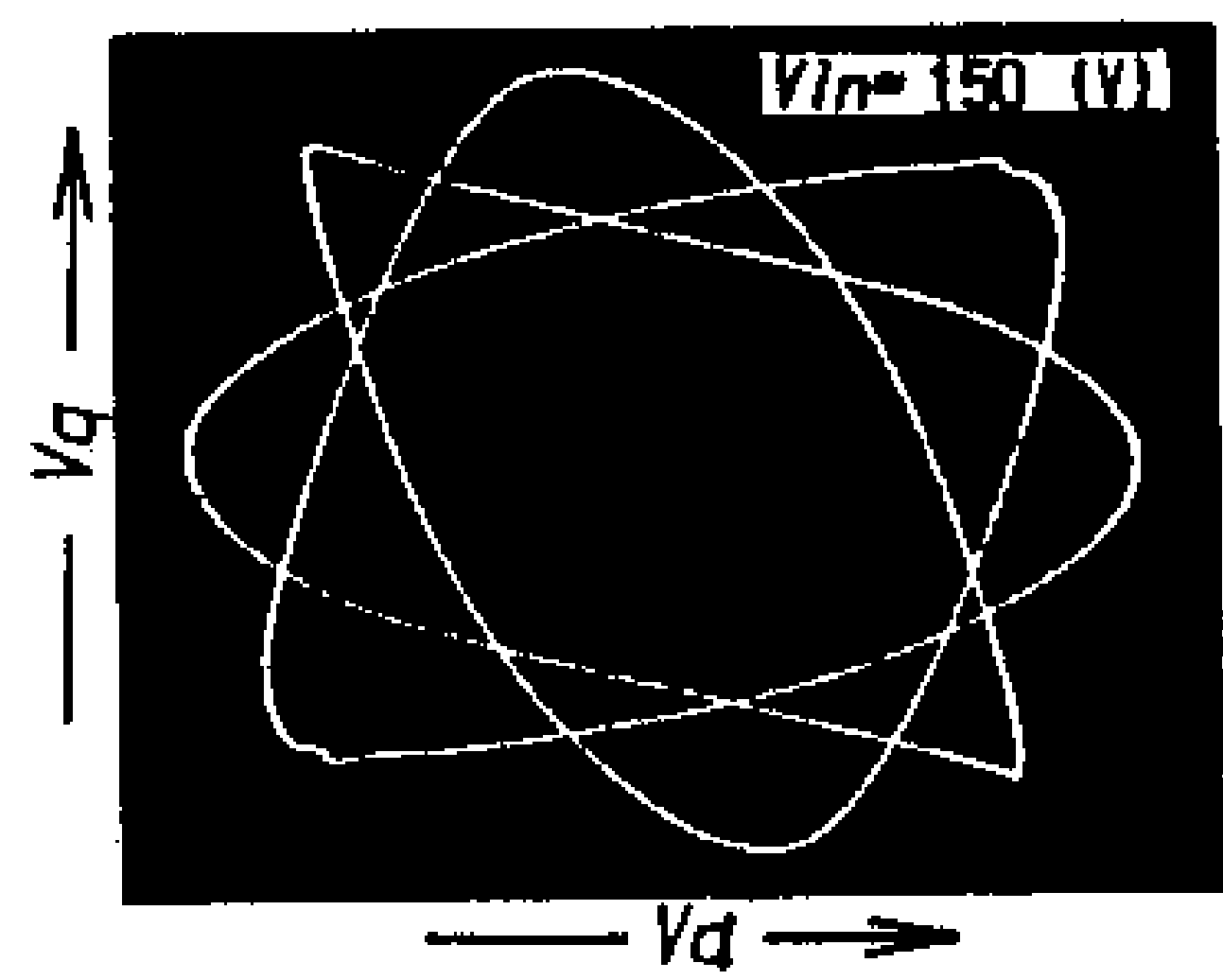

Fig.5 Lissajous 'figure of output voltages $\mathrm{V}_{\mathrm{d}}, \mathrm{v}_{\mathrm{q}}$

$\mathrm{Vd}$ and $\mathrm{Vq}$. The fundamental component mainly disturbs the waveform of third harmonic voltages.

Figure 6 shows the relation between an input voltage and a rotational speed. As an input voltage is low (Vin<l20V), the fundamental component of the flux at the poles is major and the rotor rotates near the $3600 \mathrm{rpm}$. As an input voltage increases more than $120 \mathrm{~V}$, the third component produces a highspeed rotation near $10800 \mathrm{rpm}$. The negative value of the rotational speed indicates the reverse of the rotation direction.

Figure 7 shows the torque-speed characteristics. As the results, the curve is similar to one of a three-phase induction motor. The starting torque of the hybrid motor is remarkably increased in comparison with the former. The fundamental component decreases the torque near a rotational speed of $3600 \mathrm{rpm}$. The maximum mechanical output and efficiency are $158 \mathrm{~W}, 12.5 \%$

\section{(2) Analysis of the torque-speed curve}

To examine the basic characteristics of the hybrid motor, the equivalent circuit for the third harmonic component is introduced. Figure 8 shows the basic equivalent circuit for each pole of the two-phase motor. The rightside circuit is for the tripler on the magnetic pole. The equivalent circuit of the rotor is similar to the conventional one. The value s indicates the slip of rotor.

Figure 9 shows the characteristics of third harmonic as a function of a resonant capacitor on the lock test( 1 ip $s=0)$. The same 


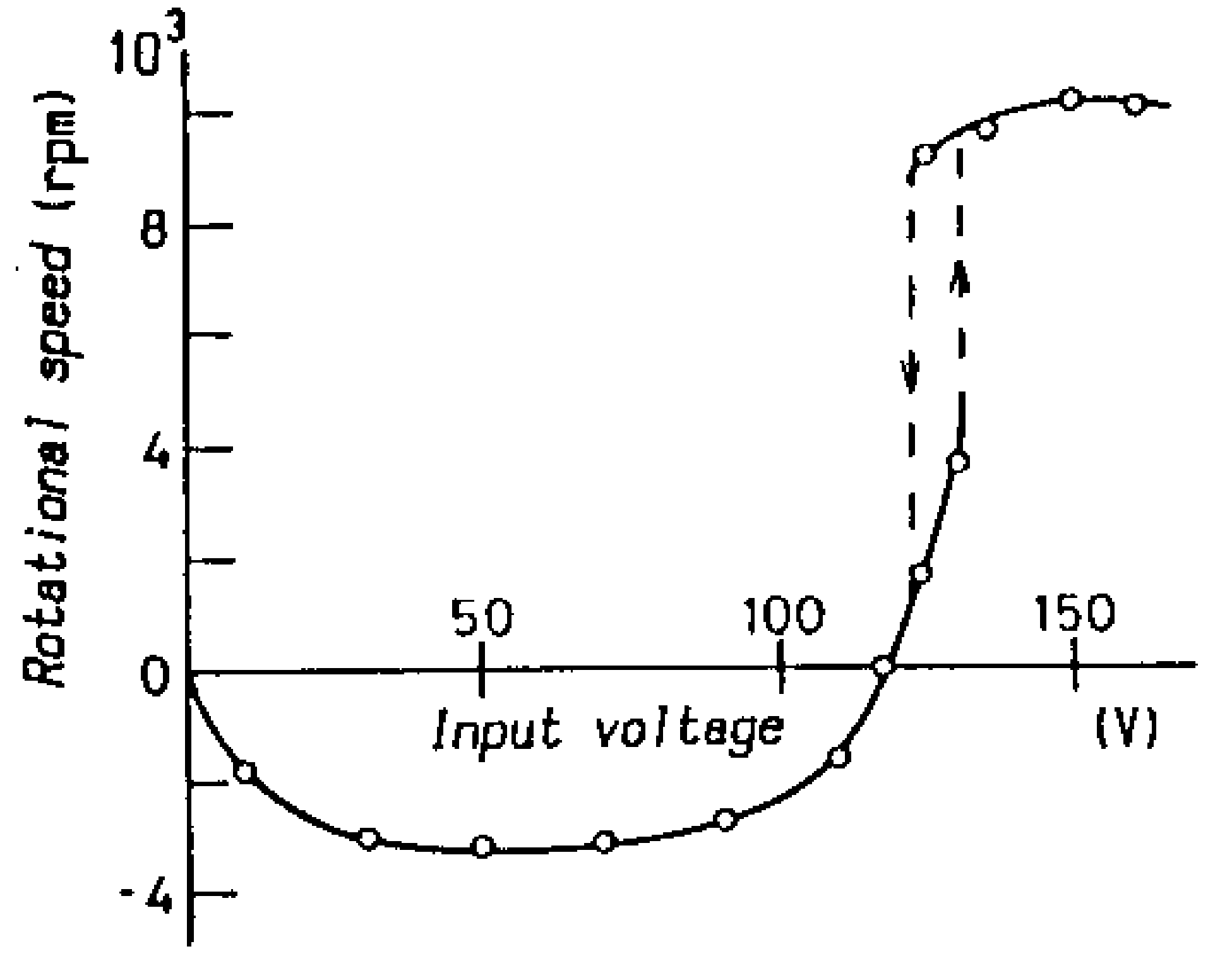

Fig.6 Rotational speed vs. input voltage

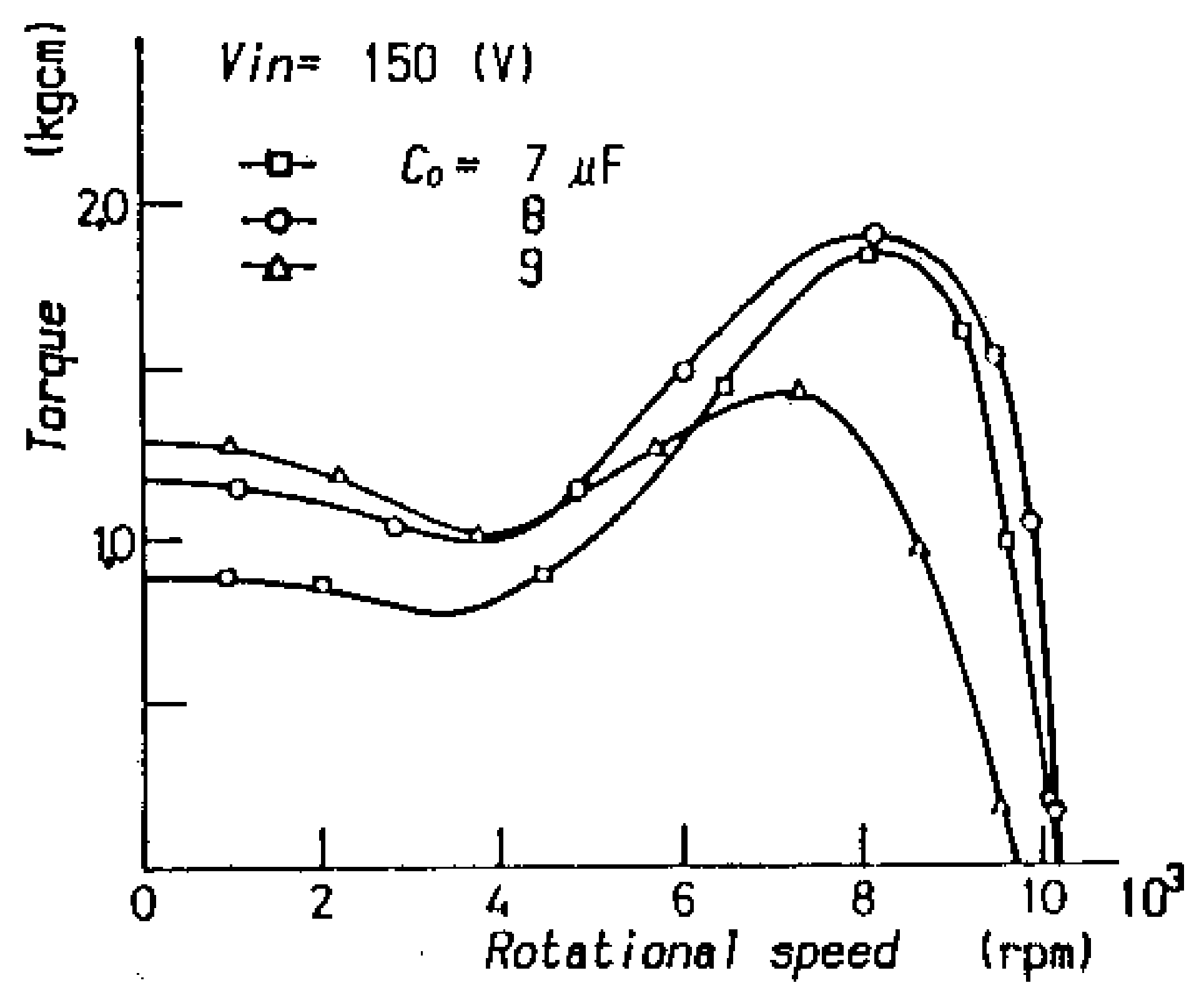

Fig. 7 Torque-speed characteristics

characteristic is measured on the no-load test( $\operatorname{sip} s=0$ ). As the results, values of the elements are obtained as,

$$
\begin{array}{ll}
\mathrm{J}=0.9 \mathrm{~A}^{-3}, & \mathrm{~b}_{\mathrm{o}}=8.65 * 10^{-3} \mathrm{~S}, \\
\mathrm{~g}_{\mathrm{O}}=1.5 * 10^{-3} \mathrm{~S}, & \mathrm{x}_{2}=320 \Omega \\
\mathbf{r}_{2}=285 \Omega &
\end{array}
$$

where each value is converted on the winding Nc.

Figure 10 shows the torque-speed curve calculated on the equivalent circuit. The curve corresponds to the experimental characteristics shown in Fig.7. Comparing two curves, the characteristics are similar each other on a high-speed operation but the decrease of the torque is remarkable below the rotational speed $8000 \mathrm{rpm}$. The fundamental component distinctly decreases the torque. It is important to reduce the fundamental component of flux for the improvement of a torque characteristic,

\section{CONCLUSIONS}

The new high-speed motor with the combination of a magnetic frequency tripler and an induction motor has been proposed. The motor has the high-speed operation and the high starting torque by supplying only the $60 \mathrm{~Hz}$ commercial source.

Compared with a conventional high-speed motor, the motor has the defects to improved. But as the motor has no semiconductor device and the brushless structure, it may be possible to apply it to the high-speed motor under a bad envi ronment.

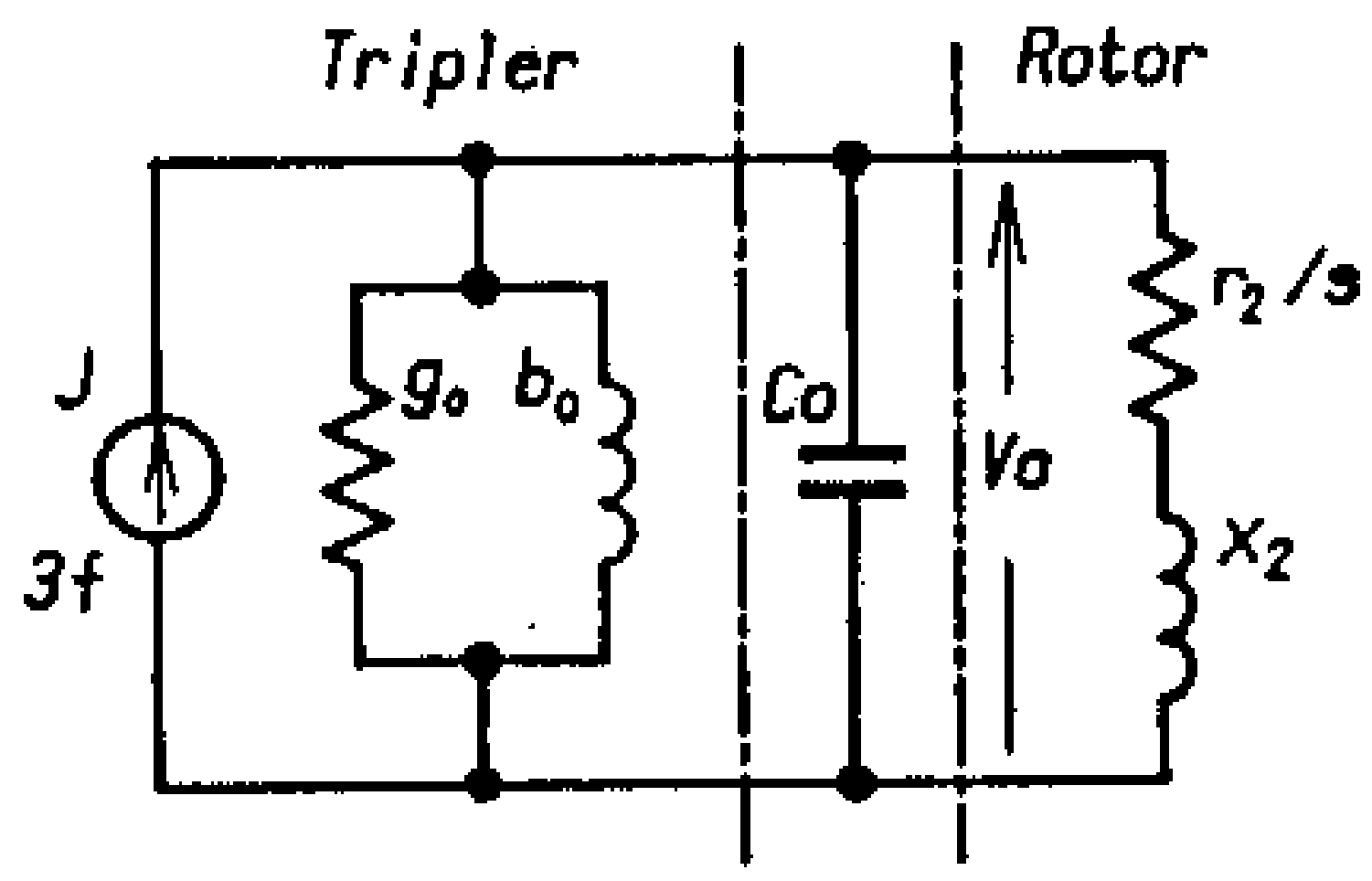

Fig.8 Equivalent circuit of the motor for third harmonic

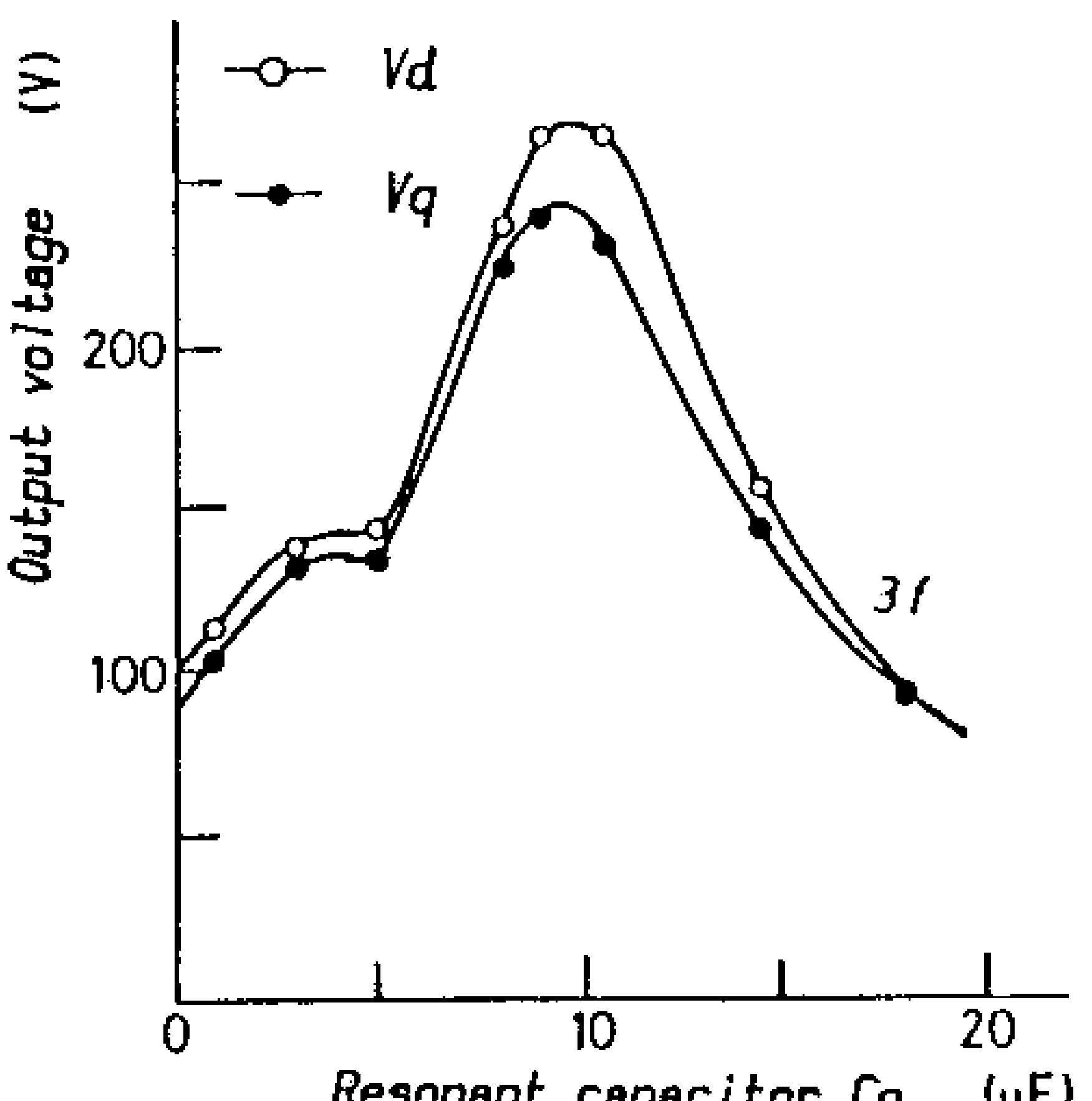

Resonant capacitor co $(\mu \mathrm{F})$

Fig. 9 Third harmonic of output voltages as a function of resonant capacitor Co

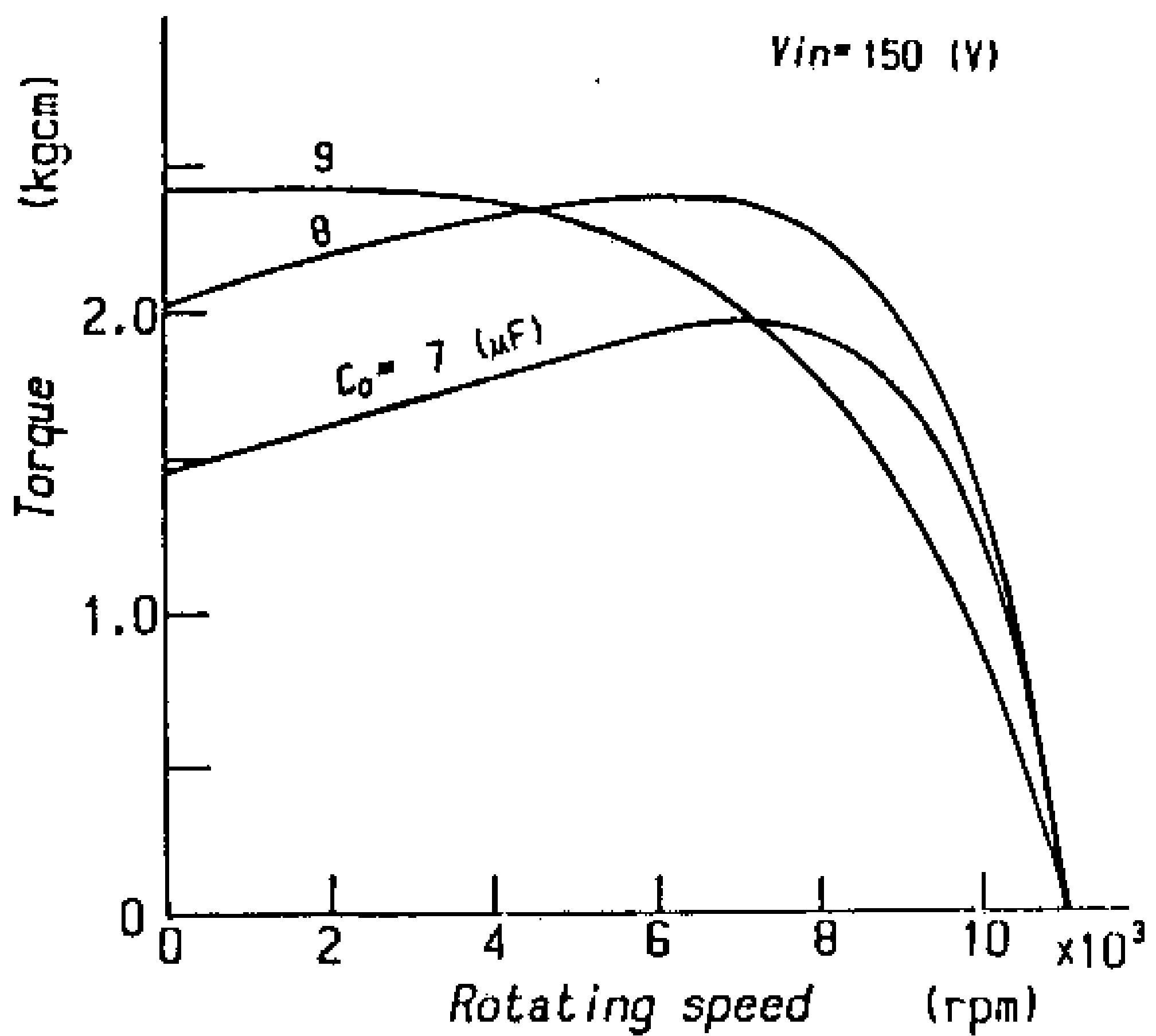

Fig.10 Torque-speed curve calculated at the equivalent circuit

\section{REFERENCES}

[1] S.Yamada, A.Takeuchi, T.Sudani, K.Bessho "High-speed AC Motor Including the Function of a Magnetic Frequency Tripler", IEEE Trans, Magnetics, Vol.MAG-22, No.s, $967-$ $989,184$.

[2] K.Bessho, S.Yamada, T.Sudani, Y.Kanamaru;"Some Experiments and Considerations on the Behavior of a New Magnetic Frequency Tripler with Bridge-connected Reactor Circuit", IEEE Trans. Magnetics, Vol.MAG12, No.6, 829-831, ד7

[3] T.Sudani, S.Yamadi, K. Bessho: "Numerical Analysis of a New Magnetic Frequency Tripler with Series-connected Reactors", IEEE Trans. Magnetics, Vol.MAG-15, No.6. $1788-1790,79$. 